\title{
Changes of Land Use and Functions of Ecosystem Service: A Case Study in China
}

\author{
Xuncheng Fan', Jianbin Liu², Jianzhong Chen², Lili Zhao ${ }^{3}$, Wei Hong ${ }^{1 *}$ \\ ${ }^{1}$ Forestry College, Fujian Agriculture and Forestry University, Fuzhou, China \\ ${ }^{2}$ Forestry Bureau of Jianyang Distrct in Nanping City, Nanping, China \\ ${ }^{3}$ College of Urban and Rural Construction, Shaoyang College, Shaoyang, China
}

Received: 23 November 2017

Accepted: 2 January 2018

\begin{abstract}
We studied the quantity and spatial and dynamic changes of land use and ecosystem service functions in Nanping City from 1995 to 2015 using of Landsat TM / ETM images in 1995, 2000, 2005, 2005, and 2015. The results show that the main land use types in the study area were forest land, cultivated land, and grassland, and the rapid growth rate of forest land was in sharp contrast with the decrease of cultivated land. In the conversion of six land use types, conversions among the forest land, cultivated land, and grassland were the most frequent. The forest was spatially schistose distribution and the grassland was clustered in the central and eastern parts, and the construction land was clustered to the central urban area, and the cultivated land was particularly broken, and the distribution pattern changes of the water area and unused land were not obvious. The dynamic changes of cultivated land, construction land, and unused land were more intense and their stability were worse, and the activity of land use in the study area was also increasing. The value of ecosystem services in Nanping was on the rise, and the contribution rate of forest ecosystem services was the highest, which accounted for more than $85 \%$ of the whole ecosystem service function, followed by grassland and cultivated land. The contribution rate of water area and unused land decreased less, while the contribution rate of unused land was minimal. Population is one of the driving factors that affect land use changes and the value of ecosystem services in Nanping.
\end{abstract}

Keywords: land use, ecosystem services, changes for 20 years, remote sensing, Nanping

\section{Introduction}

Land use is the process in which land cover can be changed by human beings by adopting certain technical means in order to rehabilitate the land purposefully and systematically [1]. Ecosystem services are produced by ecosystems and provide tangible and intangible services to human beings [1-3]. Changes in the spatial

*e-mail: 15727435965@126.com pattern of land use alter the structure and function of ecosystems and then affect ecosystem services [4]. The city of Nanping is the birthplace of Mother River (Minjiang), and its own jurisdiction to Wuyishan, which has been voted the dual heritage of world culture and nature. Consequently, it is important that changes in regional land use and ecosystem services directly affect the ecological and environmental safety of Minjiang River Basin [5]. The economy of Nanping (including Wuyishan) has developed rapidly with an annual increase of nearly 6 billion RMB in GDP in the course of 20 years 
under the vigorous support of the central and regional governments. Moreover, Nanping is still a major grainproducing area and an important industrial base in Fujian Province.

In recent years, Chinese researchers have conducted a series of comprehensive studies in Nanping on the comprehensive management of the watersheds, the diversity and value valuation of Cunninghamia lanceolata, the landscape pattern of forests, the utilization and development of bamboo resources, the intensification of rural land, and the sustainable development of agriculture, and they have proposed a large number of suggestions for future development and countermeasures. Ji et al. [6] made a preliminary study in Nanping on the changes of land use structure and the function and public value of regional ecosystem services. Liu et al. [7] analyzed the temporal and spatial changes of land use in Nanping by the use of TM images from the years 2000 and 2003.

Nanping is rich in natural resources, and the Minjiang is the largest independent inflow river in Fujian Province and the main drinking water source of the provincial capital of Fujian. At the same time, Wuyishan under the jurisdiction of the region is one of the pilot systems for 10 Chinese national parks, and the only one in Fujian Province. However, as a source of the Minjiang River and the protection of ecological environment for Fujian, the study of land use changes and ecosystem service value for Nanping have rarely been reported. In this paper we used five time series remote-sensing images from 1995, 2000, 2005, 2010, and 2015 to study the land use changes and ecosystem services value in Nanping in order to provide reference for the rational planning of land use and ecological security in the study region.

\section{Material and Methods}

\section{Study Area}

Nanping $\left(26^{\circ} 30^{\prime} \mathrm{N}\right.$ to $28^{\circ} 20^{\prime} \mathrm{N}, 117^{\circ} 00^{\prime} \mathrm{E}$ to $\left.119^{\circ} 25^{\prime} \mathrm{E}\right)$ is located in the northern part of Fujian Province
(Fig. 1). It belongs to a subtropical monsoon climate with an annual average temperature of between $17^{\circ} \mathrm{C}$ to $19^{\circ} \mathrm{C}$ and annual average rainfall of 1,684-1,780 mm. It governs 2 municipal districts, 5 counties, and 3 county-level cities covering a total area of 26,300 square $\mathrm{km}$ and accounting for about one-fifth of the total area of Fujian Province. The area of cultivated land in Nanping accounts for about $1 / 4$ of the province's arable land. Nanping is rich in forest resources with a forest coverage rate of $74.75 \%$, and the area of forest land accounts for about $1 / 4$ of the total one of the province's forest land. Livestock stockpiles account for about $1 / 3$ of the province's total.

The city has 5 provincial nature reserves, one of which is Wuyishan Natural Tourism Scenic Area, which is not only the largest nature reserve in Fujian and the most completely preserved forest ecosystem at the same latitude, but also one of only four "world nature and cultural heritage" locations in China. By the end of 2015, the total population of household registration in Nanping was 3.2 million and the permanent population was 2.64 million. In 2016 the city's GDP reached 145.774 billion yuan.

\section{Data Source and Processing}

The basic data source of this study includes Landsat TM/ETM remote sensing images of Nanping in 1995, 2000, 2005, 2010, and 2015. All data were downloaded from the Chinese Geospatial Data Cloud (www.gscloud. $\mathrm{cn}$ ). Besides the administrative map, natural and social economic statistics and a variety of non-remote sensing data in the open were collected as auxiliary data. ENVI 5.2 software was used to pre-process the remote sensing images and establish interpretation signs of the land use types in the study area. Land-use classification of the study area was conducted using the object-oriented classification method. According to the Chinese land use classification system and the geographical characteristics of Nanping, land use classification data were divided into 6 types: forest land, grassland, cultivated land, construction land, water area, and unused land.

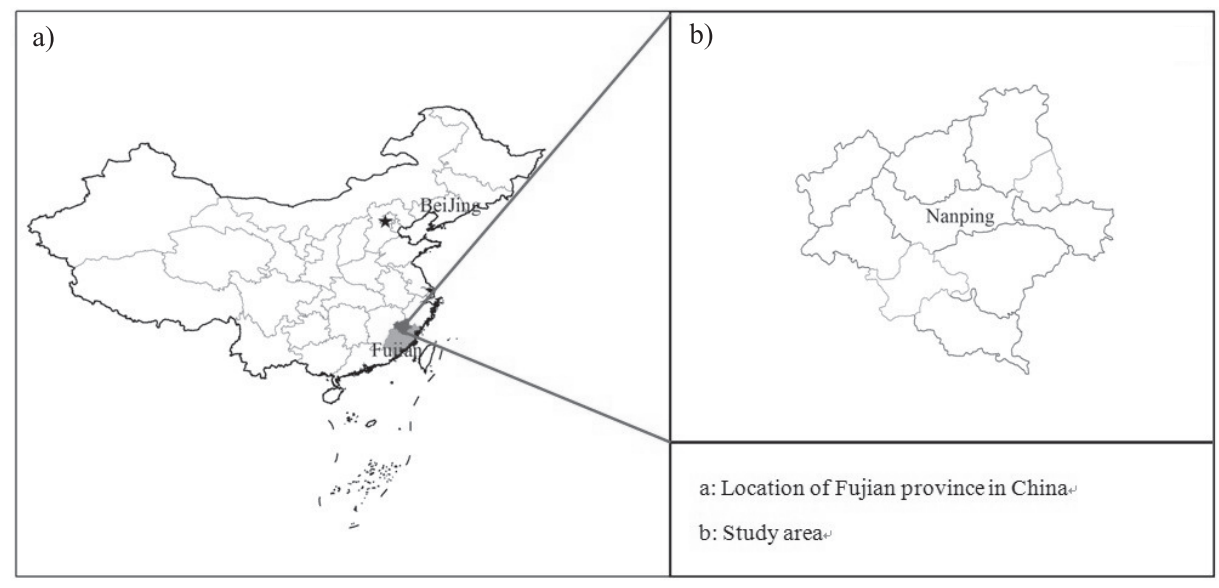

Fig. 1. Location of the study area. 


\section{Methods for Temporal LUCC}

In this paper, research about land use changes include area changes of land use, spatial changes (transfer matrix), and dynamic degree changes. The area changes of land use refer to the proportion of the area of types of land use to the total area of the study region. The area changes for several of land use types were calculated using remote sensing interpretation data for 5 time series.

The transfer matrix of land use types can be used to analyze the transformation details of different land use types [8]. Therefore, internal transitions can be analyzed more carefully. The land use transfer matrix of the study area was obtained based on the results of remote sensing classification using the computing tools of ENVI Classic 5.1.

The dynamic model of land use is a common method to describe the changes of the quantity of land resources and reflect the intensity of land use change [9]. In this paper, two kinds of models were adopted: dynamic degree of single and comprehensive land use type [10].

The dynamic degree of single land use type reflects the annual average change rate of some land use types during the study period [11], which can be expressed as follows:

$$
K=\frac{U_{b}-U_{a}}{U_{a}} \times \frac{1}{T} \times 100 \%
$$

...where $K$ is the dynamic degree of certain land use type, $U_{a}$ and $U_{b}$ are the area of the land use type at the beginning and end of study, and $\mathrm{T}$ is the length of the study.

The comprehensive dynamic degree of land use reflects the comprehensive activity and stability of land use change in the study area. The higher the value, the more active the land use change in the area and the poorer the stability [12]. Its model is:

$$
I R_{j}=\left\{\frac{\sum_{i}^{n}\left|Z_{i j b}-Z_{i j a}\right|}{2 \sum_{i}^{n} Z_{i j a}}\right\} \times \frac{1}{T} \times 100 \%
$$

...where $I R_{j}$ is the comprehensive dynamic degree of Nanping, $n$ is the total number of land use types, and $Z_{i j a}$ and $Z_{i j b}$ are the area of initial and last stages of a certain land use type.

\section{Method for Spatial LUCC}

Transfer matrix is a powerful tool to describe quantitatively the characteristics, direction, and structure of land use/cover changes in the world, and its mathematical form is as follows [8]:

$$
P_{i j}=\left[\begin{array}{cccc}
P_{11} & P_{12} & \cdots & P_{1 n} \\
P_{21} & P_{22} & \cdots & P_{2 n} \\
\vdots & \vdots & \vdots & \vdots \\
P_{n 1} & P_{n 2} & \cdots & P_{n n}
\end{array}\right]
$$

...where $P_{i j}$ represents standard area, $n$ denotes the number of land use types, $i$ and $j$ represent respectively the land use types at the beginning and end of the study period.

The maps of land use in different years were overlaid by using the overlay command of the toolbox module in ArcGIS, and the conversion area of various land use types was computed by Arcmap, and then the spatial transfer matrix of land use types was obtained. According to the number of transfer matrix, the transition probability matrix of land use change was computed.

\section{Method for Calculating Ecosystem Services Value}

In this study, the value of ecosystem services in construction land was not calculated mainly because construction land mainly consists of rural residential land and urban industrial and mining land, which destroys ecological environment due to the continuous discharge of sewage, waste gas, and solid waste to the environment with negative utility. Ecosystem service value refers to the functional utility of meeting the needs of people. This paper only calculated its positive utility of ecosystem service to people.

This study identifies 9 indicators of ecosystem services valuation, including gas regulation, climate regulation, water conservation, soil formation and protection, waste treatment, biodiversity conservation, food production, supply of raw materials, entertainment, and culture. These indexes refer to the research results of Xie et al. [13-15], and the related research results have been widely used and approved by Chinese scholars [1617]. Based on the research results of Costanza et al. [2], Xie et al. [13-15] established a value-service equivalence factor table (Table 1) for unit area of the ecosystem in China combining China's actual conditions that provided the reference for the calculation of ecosystem service value in China, and to facilitate the majority of relevant Chinese researchers [15].

Based on the equivalence table developed by Xie et al. [15] and the actual land use classification of this article, Table 1 was slightly modified to form the equivalent factor table of ecosystem services in Nanping (Table 2).

As seen in Table 2, the equivalent value per hectare of ecosystem service is based on the service value per hectare of farmland ecosystem. To obtain the service value per hectare of all ecosystems in this study area, the service value per hectare of farmland ecosystem in Nanping should be obtained firstly. The value is calculated as follows: 
Table 1. Equivalent weighting factor of ecosystem services value per hectare of terrestrial ecosystems in China.

\begin{tabular}{|c|c|c|c|c|c|c|}
\hline Indictors & Forest land & Grassland & Cultivated land & Wetland & Water area & Barren land \\
\hline Gas regulation & 3.5 & 0.8 & 0.5 & 1.8 & 0 & 0 \\
\hline Climate regulation & 2.7 & 0.9 & 0.89 & 17.1 & 0.46 & 0 \\
\hline Water conservation & 3.2 & 0.8 & 0.6 & 15.5 & 20.38 & 0.03 \\
\hline Soil formation and protection & 3.9 & 1.95 & 1.46 & 1.71 & 0.01 & 0.02 \\
\hline Waste treatment & 1.31 & 1.31 & 1.64 & 18.18 & 18.18 & 0.01 \\
\hline Biodiversity conservation & 3.26 & 1.09 & 0.71 & 2.5 & 2.49 & 0.34 \\
\hline Food production & 0.1 & 0.3 & 1 & 0.3 & 0.1 & 0.01 \\
\hline Supply of raw materials & 2.6 & 0.05 & 0.1 & 0.07 & 0.01 & 0 \\
\hline Entertainment and culture & 1.28 & 0.04 & 0.01 & 5.55 & 4.34 & 0.01 \\
\hline
\end{tabular}

Table 2. Equivalent weighting factor of ecosystem services value per hectare of terrestrial ecosystems in Nanping.

\begin{tabular}{|c|c|c|c|c|c|}
\hline & Forest land & Cultivated land & Water area & Unused land & Grassland \\
\hline Gas regulation & 3.50 & 0.50 & 0.00 & 0.00 & 0.80 \\
\hline Climate regulation & 2.70 & 0.89 & 0.46 & 0.00 & 0.90 \\
\hline Water conservation & 3.20 & 0.60 & 20.38 & 0.03 & 0.80 \\
\hline Soil formation and protection & 3.90 & 1.46 & 0.01 & 0.02 & 1.31 \\
\hline Waste treatment & 1.31 & 1.64 & 18.18 & 0.01 & 1.95 \\
\hline Biodiversity conservation & 3.26 & 0.71 & 2.49 & 0.34 & 1.09 \\
\hline Food production & 0.10 & 1.00 & 0.10 & 0.01 & 0.30 \\
\hline Supply of raw materials & 2.60 & 0.10 & 0.01 & 0.00 & 0.05 \\
\hline Entertainment and culture & 1.28 & 0.01 & 4.34 & 0.01 & 0.04 \\
\hline
\end{tabular}

$$
E_{a}=\frac{1}{7} \cdot T_{a} \cdot T_{b}
$$

...where $E_{a}$ represents the service value per hectare of farmland ecosystem in the study area (Yuan $/ \mathrm{hm}^{2}$ ), $T_{a}$ represents the average grain yield hectare of grain yield $\left(\mathrm{kg} / \mathrm{hm}^{2}\right)$ in the study area, and $T_{b}$ refers to the national average grain price (yuan $/ \mathrm{kg}$ ).

Using Equation 4, the value of farmland ecosystem services per unit area in Nanping was determined. And then we calculated the service value per unit area of other ecosystems $\left(\mathrm{CV}_{i j}\right)$ from Formula 5 and Table 1.

$$
C V_{i j}=E_{a} \cdot f_{i j}
$$

...where $C V_{i j}$ denotes a certain ecosystem service unit area value (yuan $/ \mathrm{hm}^{2} \cdot$ year) of a type of land use and $f_{i j}$ represents the equivalence factor of a kind of ecosystem service of land use type.

The calculation of ecosystem services value is as follows:

$$
E S V=\sum_{i=1} \sum_{j} A_{i} \times C V_{i j}
$$

...where $E S V$ is the total value of ecosystem services, $A_{i}$ is the area of certain land use type, and $C V_{i j}$ is a kind of ecosystem service unit value of some land use type.

\section{Results and Discussion}

\section{Quantity Changes of Land Use}

The area changes of land use types in Nanping in the past 20 years are shown in Fig. 2. The land use types between 1995 and 2015 in Nanping consisted mainly of forest land, cultivated land, and grassland accounting for more than $89 \%$ of the total study area. The area of forest land increased rapidly, increasing by $2,075.90 \mathrm{~km}^{2}$ with an increase of about 8 percentages in 20 years. The area of cultivated land fluctuated slightly. The little fluctuation was observed before 2010 


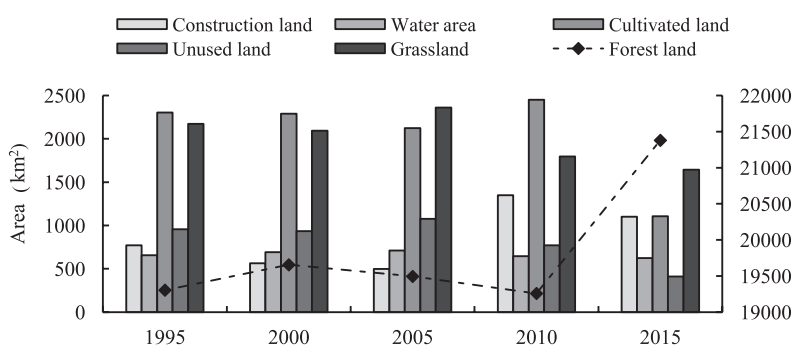

Fig. 2. Area changes of different land use types from 1995 to 2015 in Nanping.

and decreased rapidly in 2015. The area percentage of cultivated land accounted for the total area of the study region from $8.81 \%$ to $4.21 \%$, with a total area decrease of $1,198.70 \mathrm{~km}^{2}$. The grassland area decreased but still was one of the main matrices in the study area. The area for water area and unused land also decreased in varying degrees, being reduced by $32.65 \mathrm{~km}^{2}$ and $545.10 \mathrm{~km}^{2}$, respectively, over 20 years. In contrast, although the area of construction land has fluctuated, it still maintained its growth with an increase of $329.99 \mathrm{~km}^{2}$.

\section{Spatial Changes of Land Use}

In the study of land use change, the study on the area changes of land use types cannot reflect subtly the transition among different types of land, while the land use transfer matrix can effectively reveal the specific conversion among land use types [12]. On the whole, the reduced cultivated land and unused land have been mainly converted into forest land, construction land, and grassland (Table 3 ) over the past 20 years. The reduced grassland and water area have mainly been converted into forest land and construction land. The area of forest land during 20 years increased rapidly due to the conversion from other land use types and thinking highly of forest by the central government. In the meantime, Nanping is not only the main grain-producing region of Fujian Province, but also one of the most important industrial bases. In recent years, the GDP of Nanping increased from 14.594 billion yuan in 1995 to 133.951 billion in 2015, with an average annual increase of nearly
6 billion yuan. At the same time, the population in Nanping has also increased, resulting in a marked rise in construction land for housing and transportation. As can be seen from Figure 3, forest land concentrated on the western and southwestern regions of the study region with the continuous changes in the area of forest land during 20 years. The distribution of cultivated land was more fragmented. The grassland area decreased during the study period and its spatial pattern gradually shifted from the entire area to the central and eastern parts. The construction land concentrated to the central urban area after 2010. The distribution pattern of water area and unused land had no significant change.

\section{Dynamic Degree Changes of Land Use}

Table 4 shows that the change rates of all kinds of land use types in the study area were different from 1995 to 2015. The unused land was the fastest decreasing rate in all land use types, with dynamic degree of $-2.85 \%$. The rank of reduction rates of other land use categories were as follows: cultivated land $>$ pasture $>$ water area. The total population of the registered permanent residence in the study area increased rapidly from 2,939,900 in 1995 to $3,198,600$ in 2015 , with an increase of 258,700 . The rise of population inevitably occupies unused land and eventually leads to the redistribution of land use types.

In the land use types with increasing area, the area of construction land had the most dramatic change, with its dynamic degree ranking first and a value of $2.14 \%$. This was inseparable from rapid economic development over the past 20 years, the acceleration of urbanization, and the increase of population. Secondly, the area changes of forest land were also obvious, with a dynamic degree of $0.54 \%$, which was related to the policy of sticking to the development of forestry for many years. In terms of phases, except for the area growth of forest land and water area, the area of remaining land categories showed a downward trend from 1995 to 2000 . Among them, the slowdown of construction land was the fastest and that of grassland was the second fastest. From 2000 to 2005 the dynamic degree of construction land continued its slowdown while that of the unused land and grassland began to increase greatly, and that of water area increased slowly. From 2005 to 2010 the dynamic degree of unused

Table 3. Land use transfer probability matrix from 1995 to 2015 in Nanping (\%).

\begin{tabular}{|c|c|c|c|c|c|c|}
\hline 2015 & Construction land & Forest land & Water area & Cultivated land & Unused land & Grassland \\
\hline Construction land & 22.36 & 6.05 & 10.83 & 20.60 & 11.04 & 7.08 \\
\hline Forest land & 57.68 & 83.36 & 64.96 & 47.55 & 53.74 & 65.35 \\
\hline Water area & 11.60 & 2.55 & 15.86 & 3.10 & 1.85 & 1.52 \\
\hline Cultivated land & 3.36 & 1.15 & 1.95 & 8.14 & 4.43 & 2.68 \\
\hline Unused land & 0.20 & 0.10 & 0.16 & 0.53 & 0.50 & 0.28 \\
\hline Grassland & 4.80 & 6.79 & 6.24 & 20.08 & 28.44 & 23.09 \\
\hline
\end{tabular}



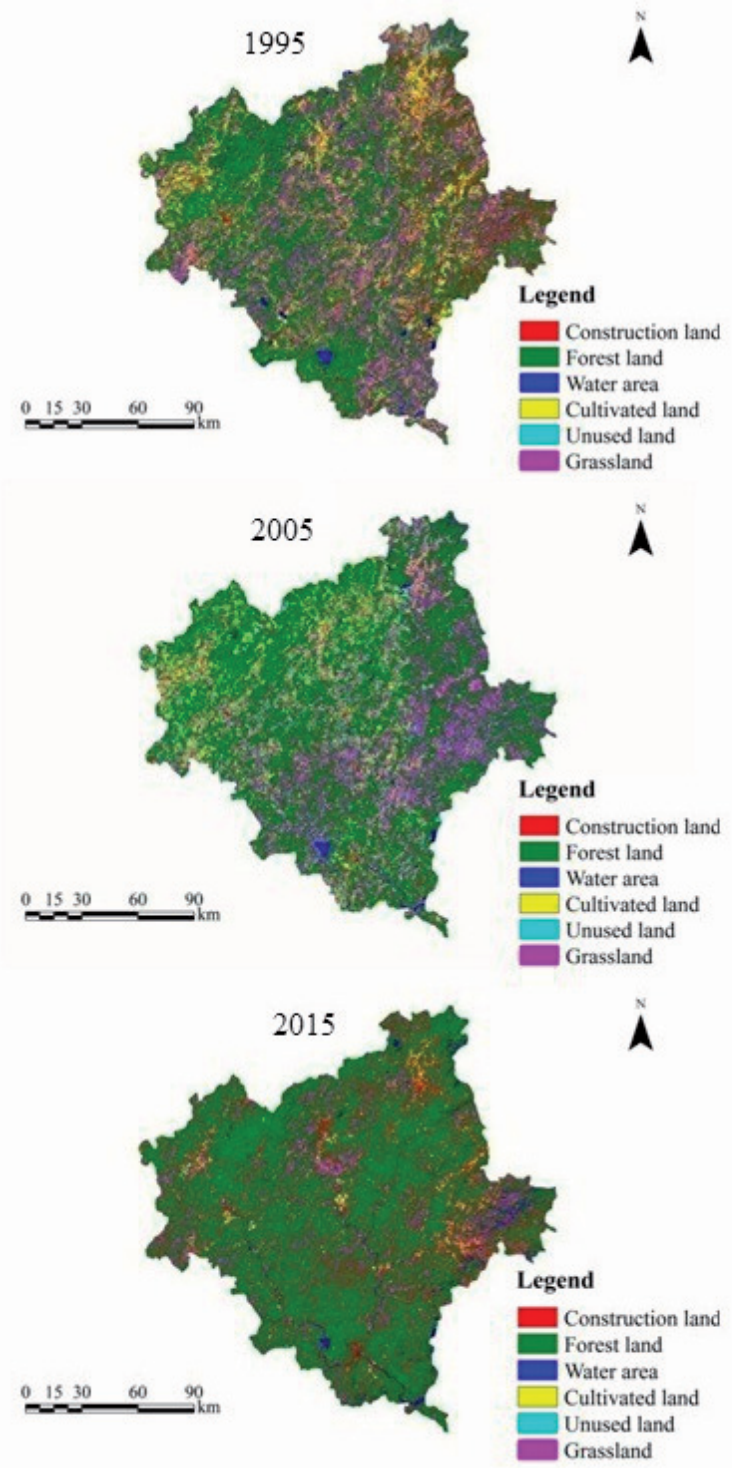
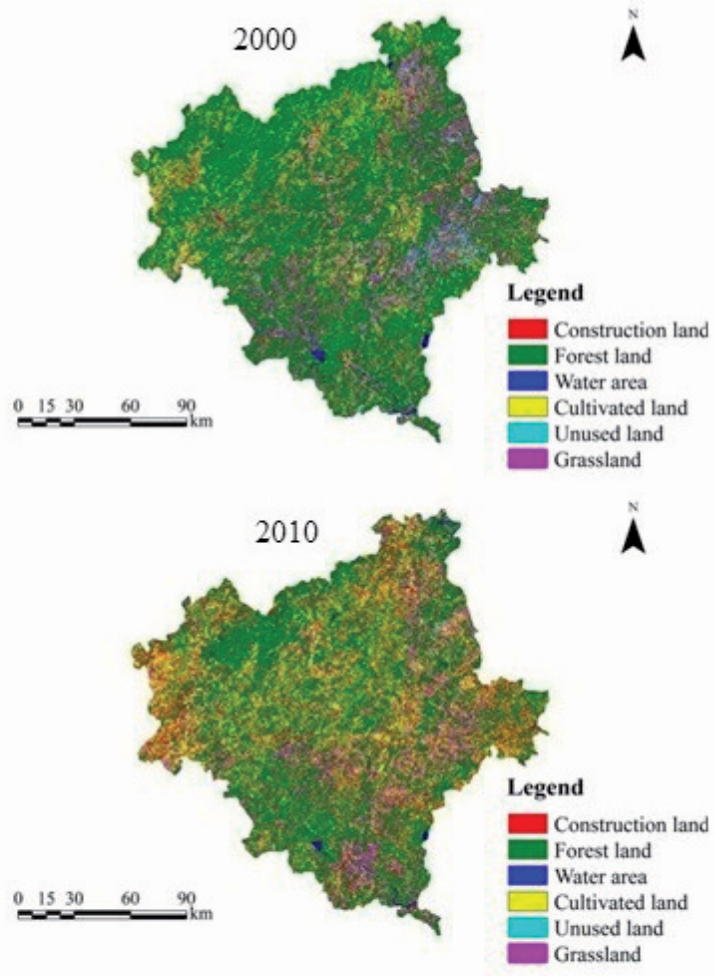

Fig. 3. Spatial distribution of various land use types in the study area, 1995-2015.

land was the largest among the area decreasing land use types with a value of $-5.69 \%$. In contrast, the growth trend of construction land was significant, with a value of $34.13 \%$. From 2010 to 2015 , except for the dynamic range of forest land being positive, the values of other land use types were all negative, indicating that the increase of forest land during this period was significant. In the remaining land types, the decrease of cultivated land was the most intense, reaching $-10.98 \%$, followed by unutilized land, and construction land showed a slight downward trend.

Table 4. Dynamic degree of various land use types in Nanping (\%).

\begin{tabular}{|c|c|c|c|c|c|}
\hline Land use types & $1995-2000$ & $2000-2005$ & $2005-2010$ & $2010-2015$ & $1995-2015$ \\
\hline Unused land & -0.43 & 3.04 & -5.69 & -9.35 & -2.85 \\
\hline Construction land & -5.42 & -2.26 & 34.13 & -3.68 & 2.14 \\
\hline Forest land & 0.36 & -0.16 & -0.24 & 2.20 & 0.54 \\
\hline Grassland & -0.72 & 2.56 & -4.79 & -1.69 & -1.22 \\
\hline Water area & 1.04 & 0.59 & -1.86 & -0.65 & -0.25 \\
\hline Cultivated land & -0.14 & -1.44 & 3.09 & -10.98 & -2.60 \\
\hline
\end{tabular}


Table 5. Values of ecosystem services function in Nanping (hundred million yuan).

\begin{tabular}{|c|c|c|c|c|c|}
\hline Land use types & 1995 & 2000 & 2005 & 2010 & 2015 \\
\hline Forest land & $1,800.037$ & $1,832.796$ & $1,817.793$ & $1,795.762$ & $1,993.601$ \\
\hline Cultivated land & 67.994 & 67.527 & 62.661 & 72.344 & 32.636 \\
\hline Water area & 128.957 & 135.640 & 139.660 & 126.657 & 122.553 \\
\hline Unused land & 1.711 & 1.674 & 1.929 & 1.380 & 0.735 \\
\hline Grassland & 67.120 & 64.706 & 72.979 & 55.494 & 50.808 \\
\hline Total & $2,065.820$ & $2,102.342$ & $2,095.022$ & $2,051.637$ & $2,200.334$ \\
\hline
\end{tabular}

According to Formula 2, the comprehensive dynamic ranges of land use in the study area from 1995 to 2000, from 2000 to 2005, from 2005 to 2010 , and from 2010 to 2015 were, respectively, $0.27 \%, 0.31 \%, 0.90 \%$, and $1.62 \%$. We found that the comprehensive utilization of land use dynamic trends above 4 periods were on the rise, indicating that the rate of land use change in the study area continued to accelerate, that is to say under the combined effect of natural and human factors, land use intensity of the study area became larger and overall stability worsened.

\section{Change in Ecosystem Service Value}

The ecosystem service value of different land use types in Nanping and their contribution rates from 1995 to 2015 are shown in Table 5 and Figure 4. Although the value of ecosystem services in the study region has fluctuated over the past 20 years, it has generally risen. Its functional value has increased from 206.5820 billion yuan in 1995 to 220.0334 billion yuan in 2015, with a total increase of 13.4514 billion yuan during 20 years and an average annual increase of 672.6 million yuan. In terms of land use types, the functional value of forest land ecosystems increased most, with a contribution rate of more than $85 \%$. Its value increased from 180.0037 billion yuan in 1995 to 199.3601 billion yuan in 2015, with a total increase of 19.3564 billion yuan and annual average increase of 0.9678 million yuan. Cultivated land remained relatively stable until 2005 , with an increase in 2010 reaching a value of 7.2344 billion yuan. In 2015 the value of cultivated land plummeted and the functional value dropped to 3.2636 billion yuan, decreasing by

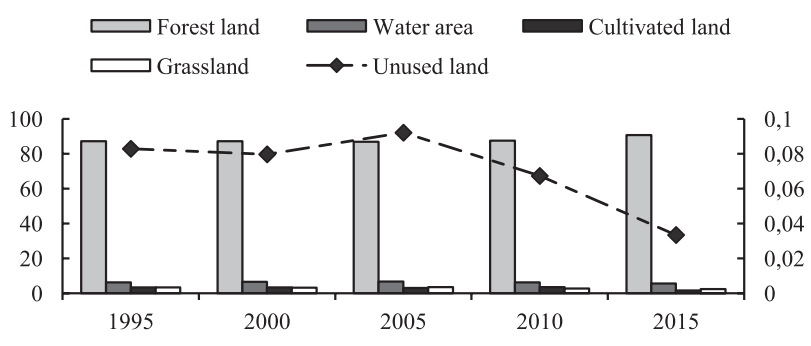

Fig. 4. The contribution rate of ecosystem service values in different land use types from 1995 to 2015 (\%).
3.5358 billion yuan in 20 years. In addition to the increased functional value of grassland in 2005, the value of the one in the rest period showed a gradually decreasing trend with a total decrease of 1.6312 billion yuan and an average annual reduction of 0.0816 million yuan and a contribution rate of between $1.5 \%$ and $3.5 \%$. The functional value of the water area ecosystem remained generally stable, only increasing between 2000 and 2005, and then gradually decreasing to a level similar to the functional value of 1995 , showing a slight reduction over 20 years with a total reduction of 0.6406 billion. The contribution rate put water area behind forest land and its value was above $5 \%$. The functional value of unused land generally was slowly decreasing, with a total reduction of 0.0976 billion yuan in 20 years and a very low contribution rate of less than $0.1 \%$.

We can see from Table 6 that the order of service value of various ecosystem service types in Nanping from 1995 to 2015 is as follows: waste treatment > water conservation $>$ gas regulation $>$ biodiversity conservation $>$ raw materials $>$ soil formation and protection $>$ entertainment culture $>$ food produce. For the rapid development of Nanping, waste disposal is of great significance and the service value of gas regulation, water, and biodiversity conservation were all above 30 billion yuan. Therefore, waste disposal and the protection of biodiversity and forest land should be strengthened in Nanping so that the value of water conservation, biodiversity, and gas regulation continue to be maintained at a relatively high level. During the study, a large increase on the area of forest land made a significant rise on the service value of most of ecosystem service types, such as gas regulation and water conservation. At each stage, the ecosystem service value in Nanping fluctuated less mainly because of the obscure changes in land use types and the high percentage of the area of forest land.

\section{Influence of Population on Land Use and Ecosystem Service Value}

Population is one of the most active drivers of land use changes [18]. Changes of population directly lead to changes in land use type, thereby affecting the value of ecosystem services. Humans need to continually rehabilitate land to accommodate the changing population. Figure 5 shows that the population of Nanping has shown 
Table 6. The values of ecosystem services in Nanping (hundred million yuan).

\begin{tabular}{|c|c|c|c|c|c|}
\hline Ecosystem service & 1995 & 2000 & 2005 & 2010 & 2015 \\
\hline Gas regulation & 300.62 & 305.56 & 303.72 & 298.96 & 327.26 \\
\hline Climate regulation & 240.78 & 244.53 & 243.12 & 239.34 & 258.05 \\
\hline Water conservation & 334.52 & 341.97 & 342.06 & 331.94 & 355.11 \\
\hline Waste treatment & 347.84 & 353.15 & 350.96 & 345.88 & 371.92 \\
\hline Soil formation and protection & 193.19 & 197.03 & 198.80 & 189.91 & 189.43 \\
\hline Biodiversity conservation & 293.97 & 298.78 & 297.71 & 291.64 & 315.62 \\
\hline Food production & 18.39 & 18.49 & 17.73 & 18.99 & 14.13 \\
\hline Supply of raw materials & 215.63 & 219.50 & 217.70 & 215.10 & 238.03 \\
\hline Entertainment and culture & 118.11 & 120.65 & 120.19 & 117.58 & 128.68 \\
\hline Total & $2,063.04$ & $2,099.66$ & $2,092.00$ & $2,049.34$ & $2,198.23$ \\
\hline
\end{tabular}

a significant upward trend, increasing from 2,939,900 in 1995 to $3,198,600$ in 2015 , with an increase of 258,700 over 20 years. The increase in population in Nanping over 20 years was bound to lead to changes in land use and cover, finally resulting in changes to the ecosystem services value. The specific performances of land use changes were the construction of large-scale facilities such as water, electricity, and early warning facilities, and daily facilities such as landfill, recreational facilities, water supply system, resident health information system, school information, and other convenient service facilities. The construction of these facilities affected the spatial distribution of land use and cover, and the value of ecosystem services in Nanping.

In this paper, it can be found that population growth in Nanping has led to a marked increase in the area of construction land over 20 years, and a significant reduction in the area of cultivated land. The area of construction land in Nanping increased by $329.99 \mathrm{~km}^{2}$, and that of cultivated land decreased by $1,198.7 \mathrm{~km}^{2}$ over 20 years. Land for construction was one of the main conversion types of cultivated land, indicating that population growth inevitably required more housing and residential facilities, resulting in more cultivated land being turned to construction land. At the same time,

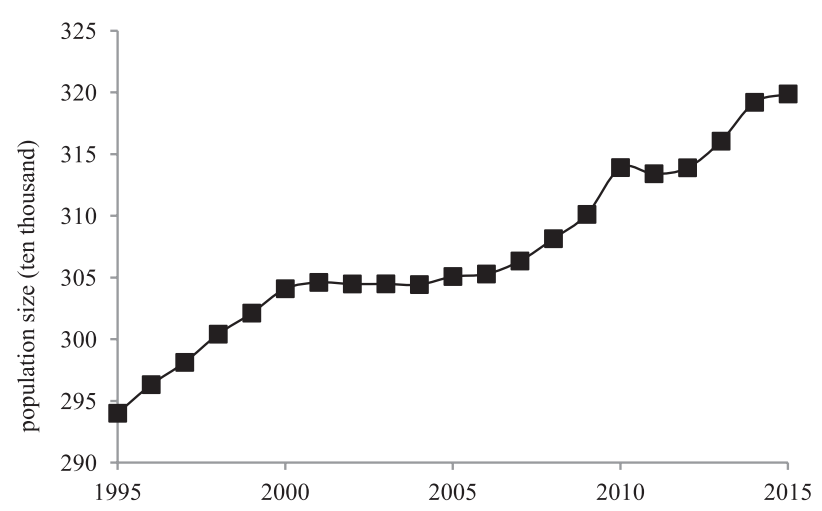

Fig. 5. Changes of population in Nanping over 20 years. cultivated land is the main source of food. The rapid population growth and the conversion of more cultivated land into construction land inevitably led to a tight and insufficient food supply. Therefore, it is a crucial issue how to solve the contradiction between population and cultivated land. Controlling the population and improving grain productivity per unit area of cultivated land can effectively alleviate the problem of insufficient grain supply caused by population growth.

Land use is a relatively close link between man and nature, and land use changes affect the structure and function of ecosystems [19], and then the value of ecosystem services. In order to make a comparison with similar research [20-21], the method of Costanza et al. and Xie et al. $[2,15]$ was used to estimate the value of ecosystem services in Nanping.

However, due to lagging awareness and the diversity of ecosystem service values [22], it is difficult to accurately estimate the value of ecosystem services [2]. For example, changes in the landscape index of a study region, such as the number of patches, the average plate area, and the degree of aggregation, will inevitably have an impact on ecosystem service value, although there is no change in the area of land use type. Therefore, many scholars have pointed out that more studies about the assessment on ecosystem service value should be implemented in the different spatial levels and scales [23].

Although the function types of ecosystem service in this paper were relatively fewer, it still is a feasible research paradigm, and it is helpful to incorporate the results of scientific research into management decisions. In order that the research results are accepted and applied easily, we need to improve the assessment method, simulate more ecosystem services, synthesize the simulation results, and display the results with intuitive and transparent indicators.

How to achieve optimal development to comprehensively manage various ecosystem service functions under the help of taking reasonable management measures has always been the focus [24-27]. 
Bennett [28] considered that taking measures to common driving force for different ecosystem service functions can effectively promote the coordinated development of multiple service functions. In this paper, land use change is the common driving force. On the basis of the impact of explicit land-use type changes on ecosystem service functions, decision makers can achieve sustainable management by developing appropriate land-use plans [29-30], which is of great significance for understanding the changes of regional ecological environment and promoting the coordinated development of a regional economy [31-32].

\section{Conclusions}

Based on the remote sensing interpretation data for 5 time series, we conducted quantitative analysis of the area changes, conversion feature, and dynamic degree of land use in Nanping. The results showed that during the study period, the main land use types in Nanping were forest land, grassland, and cultivated land, and the sum of the 3 accounted for more than $89 \%$ of the total area of the study area. The area of forest land and construction land increased obviously. Among them, the area of forest land increased by $2,075.90 \mathrm{~km}^{2}$ in 20 years, compared with the most severe decrease of cultivated land and a reduction of $1,198.70 \mathrm{~km}^{2}$.

Although the conversion among different land use types in the study area was slightly different at all stages, the mutual conversion of forest land, farmland, and grassland was still the main one. The newly increased forest land mainly came from cultivated land, grassland, and water area. A large proportion was accounted for by the decreased cultivated land converting to construction land and grassland in addition to converting to forest land.

In terms of the dynamic degree of land use types, unused land had the highest value of dynamic movement among land use types with reduced dynamic degree (up to $-2.85 \%$ ), followed by cultivated land. In contrast, among land use types with the increased one, the changes of construction land were the most dramatic and forest land ranked second. Judging from the comprehensive dynamic of land use in each stage, it showed a gradual increase and land use activity gradually strengthened.

From 1995 to 2015, the value of ecosystem services in Nanping showed an overall upward trend, increasing by 13.4514 billion yuan over the past 20 years. Among them, the contribution rate of forest ecosystem services was more than $85 \%$. The contribution rate of the ecosystem service value of grassland and cultivated land remained between $1.5 \%$ and $3.5 \%$. The one of water area and unused land was a lower rate of decline and the one of unused land was less than $0.1 \%$. The order of functional value of ecosystem services in Nanping are listed as follows: waste treatment $>$ water conservation $>$ gas regulation $>$ biodiversity conservation $>$ raw materials $>$ soil formation and protection $>$ entertainment culture $>$ food production.

The population in Nanping showed a rapid increase from 1995 to 2015 . The increase in the population led to land use changes, which in turn affected the ecosystem service value. Therefore, population is the driving factor of land use change in Nanping. However, the driving forces influencing land use change are complex and comprehensive, which should also include socioeconomic factors such as economy, policy, urbanization, and transportation systems, as well as natural factors such as slope and elevation. Therefore, the next paper should study the driving forces of land use change in order to reveal fully and deeply the influence of these factors on land use change and ecosystem services value.

Land is a basic and crucial resource for economic development. The dynamic change of land use is an important foundation for the study of rational planning of land resources. Based on the geographical characteristics of the study area, this study divided land classification of the whole study area into 6 kinds of land use types and quantitatively analyzed their land use status over the past 20 years. The results can provide reference for the rational utilization of land resources in the study area. However, in the quantitative analysis, the detailed analysis of regional difference of land use change in county-level cities and counties within the jurisdiction of Nanping has not yet been implemented, and the concrete conversion processes and changes of land use in these places are still not fully understood. The content of these aspects is yet to be further improved.

\section{Acknowledgements}

The authors are grateful to the National Science and Technology Major Project of the Ministry of Science and Technology of China (fund No. 2017YFD0601304) for financial support.

\section{Conflict of Interest}

The authors declare no conflict of interest.

\section{References}

1. FU B.J., ZHANG L. Land-use change and ecosystem services: concepts, methods and progress. Progress in Geography. 33 (4), 441, 2014.

2. COSTANZA R., D'ARGE R., GROOT R.D., FARBER S., GRASSO M., HANNON B., LIMBURG K., NAEEM S., O'NEILL R.V., PARUELO J. The value of the world's ecosystem services and natural capital. Nature. 387 (1), 3, 1997.

3. DAILY G.C. Nature's services: societal dependence on natural ecosystems. Pacific Conservation Biology. 6 (2), 220, 1997.

4. WANG X., DONG X., LIU H., WEI H., FAN W., LU N., XU Z., REN J., XING K. Linking land use change, 
ecosystem services and human well-being: A case study of the Manas River Basin of Xinjiang, China. Ecosystem Services. 27 (A), 113, 2017.

5. HU X., HONG W., WU C. Evaluation of service function value of land ecosystem in Fuzhou. Journal of Northeast Forestry University. 39 (12), 90, 2011.

6. JI G.Z., WU C.Z., HONG W. Study on Nanping city urbanization driving force. Territory and Natural Resources Study. (4), 38, 2012.

7. LIU J., QI X.L., YU K.Y., HUANG W.Y., WANG W.M., CHEN M.H. Spatio-temporal changes analysis on land use of Nanping City based on RS and GIS. Journal of Fujian College of Forestry. 26 (1), 10, 2006.

8. YANG J., WANG C.Q., XIA J.G., ZHANG W.X., BAI G.C., ZHANG Y. Spatial planning of land use based on cellular automata modelin-a case study of Dongpo District, Meishan City. Acta Pedologica Sinica. 47 (5), 847, 2010.

9. LIU S.H., HE S.J. The calculation model of spatial analysis of land use dynamic changes. Journal of Natural Resources. 17 (05), 533, 2002.

10. GAO W., CHEN Y., MIN X.U., GUO H., XIE Y. Trend and driving factors of water quality change in Lake Fuxian(1980-2011). Journal of Lake Sciences. 25 (5), 635, 2013.

11. LIU J., ZHANG Z., ZHUANG D. A study on the spatialtemporal dynamic changes of land-use and driving forces analyses of China in the 1990s. Geographical Research. 6 (3), 38, 2003.

12. ZHOU Y., BAI X., JIANG J. Dynamic land use changes in the Poyang Lake region over the recent 17 years. Resources Science. 36 (06), 1186, 2011.

13. XIE G.D., LIN Z., LU C.X., YU X., CAO C. Expert knowledge based valuation method of ecosystem services in China. Journal of Natural Resources. 23 (5), 911, 2008.

14. XIE G., XIAO Y., LU C. Study on ecosystem services: progress, limitation and basic paradigm. Journal of Plant Ecology. 30 (2), 191, 2006.

15. XIE G., CHUN L.U., LENG Y., ZHENG D., SHUANG L.I. Ecological assets valuation of the Tibetan Plateau. Journal of Natural Resources. 18 (2), 189, 2003.

16. ZHANG Y., GUAN D., ZHAI J., DENG W. Spatial and temporal variations of ecosystem services value in Chongqing City. Acta Scientiae Circumstantiae. 37 (3), 1169, 2017.

17. ZHANG H.T., DU H.S., WANG S.D., LEI J. Study on the land use change and ecosystem services value in Changbai Mountain. Research of Soil \& Water Conservation. 19 (6), 242, 2012.

18. VAČKÁŘ D., CHOBOT K., ORLITOVÁ E. Spatial relationship between human population density, land use intensity and biodiversity in the Czech Republic. Landscape Ecology. 27 (9), 1279, 2012.

19. WU Z., DAI E.F., GE Q.S., FAN C.H. Modeling the integrated effects of land use and climate change scenarios on forest aboveground biomass: A case study in Taihe County of China. Acta Geographica Sinica. 72 (09), 1539, 2017.
20. DEAL R.L., SMITH N., GATES J. Ecosystem services to enhance sustainable forest management in the US: moving from forest service national programmes to local projects in the Pacific Northwest. Forestry. 90 (5), 632, 2017.

21. RICHARDS D.R., FRIESS D.A. Characterizing coastal ecosystem service trade-offs with future urban development in a tropical city. Environment Management. 60 (5), 961, 2017.

22. KANDULU J.M., MACDONALD D.H., DANDY G., MARCHI A. Ecosystem service impacts of urban water supply and demand management. Water Resources Management. 31 (15), 4785, 2017.

23. WANG Y.P. Study on the ecological compensation of the water source areas of the south-to-north water diversion middle routes project based on ecosystem services value. Journal of Nanyang Institute of Technology. 3 (6), 67, 2011.

24. ZIV G., BARAN E., NAM S., RODRÍGUEZITURBE I., LEVIN S.A. Trading-off fish biodiversity, food security, and hydropower in the Mekong River Basin. Proceedings of the National Academy of Sciences of the United States of America. 109 (15), 5609, 2012.

25. WARDROP D.H., GLASMEIER A.K., PETERSONSMITH J., ECKLES D., INGRAM H., BROOKS R.P. Wetland ecosystem services and coupled socioeconomic benefits through conservation practices in the Appalachian Region. Ecological Applications. 21 (21), S93, 2011.

26. WENDLAND K.J., HONZÁK M., PORTELA R., VITALE B., RUBINOFF S., RANDRIANARISOA J. Targeting and implementing payments for ecosystem services: Opportunities for bundling biodiversity conservation with carbon and water services in Madagascar. Ecological Economics. 69 (11), 2093, 2010.

27. SCHLÜTER M., LESLIE H., LEVIN S. Managing wateruse trade-offs in a semi-arid river delta to sustain multiple ecosystem services: a modeling approach. Ecological Research. 24 (3), 491, 2009.

28. BENNETT E.M., PETERSON G.D., GORDON L.J. Understanding relationships among multiple ecosystem services. Ecology Letters. 12 (12), 1394, 2009.

29. SOUTHERN A., LOVETT A., O RIORDAN T., WATKINSON A. Sustainable landscape governance: Lessons from a catchment based study in whole landscape design. Landscape \& Urban Planning. 101 (2), 179, 2011.

30. OOBA M., WANG Q., MURAKAMI S., KOHATA K. Biogeochemical model (BGC-ES) and its basin-level application for evaluating ecosystem services under forest management practices. Ecological Modelling. 221 (16), 1979, 2010.

31. HU C.X., GUO X.D., LIAN G., LIAN G. Effects of land use change on ecosystem service value in rapid urbanization areas in Yangtze River delata-A case study of Jiaxing City. Resources and Environment in the Yangtze Basin. 26 (3), 333, 2017.

32. SHI Y.Y., XIAO L., HUANG X.J., MIAO Y.U. Arable land use transitions and its response of ecosystem services value change in Jiangsu coastal areas. Journal of Natural Resources. 32 (6), 961, 2017. 